\title{
Analyzing the Effectiveness of Simulation in Promoting Learner Autonomy: Perceptions of ESP Hotel Management Students
}

\author{
Sartaj Fakhar Jilani', Musarat Yasmin 1,2* \\ ${ }^{1}$ Department of English, University of Gujrat, Gujrat, Pakistan \\ ${ }^{2}$ Department of English, University of Azad Jammu and Kashmir, Muzaffarabad, Pakistan \\ Email: *musarat.yasmin@uog.edu.pk, *musaratalvi@hotmail.com
}

Received 1 June 2016; accepted 19 July 2016; published 22 July 2016

Copyright (C) 2016 by authors and Scientific Research Publishing Inc.

This work is licensed under the Creative Commons Attribution International License (CC BY). http://creativecommons.org/licenses/by/4.0/

(c) (7) Open Access

\begin{abstract}
Simulation-based teaching with its life-long efficacy has led many researchers and educationists to probe deeply into the promotion of learner autonomy in the teaching and learning nexus. This newly emerging trend is an indication of accelerating concern in the area of global ESP perspective which has a pivotal significance regarding experimentation with interactive learning situations, eventually resulting in a broader understanding of learner autonomy along with refinement of problem-solving, decision making and critical thinking skills. The ultimate goal of the present study was to evaluate the effectiveness of simulation in nurturing learner autonomy. It further scrutinized the perceptions and beliefs of 40 ESP Hotel Management students (L2 learners) enrolled in University of Gujrat (UOG), purposively selected, whose responses regarding simulation as a dynamic teaching tool, contributing actively in enhancing learner autonomy or not, were eventually examined. In this perspective the researchers designed a closed-ended questionnaire. Findings of the study revealed that simulation integrated in innovative and interactive learning scenarios stimulates the learning and enhances learner autonomy by increasing learner motivation, encouraging team work, developing communication, interpersonal and project management skills while boosting up learners' confidence in task-based ventures and collaborative learning along with enrichment of workplace skills in multidimensional situations and in a tension free environment.
\end{abstract}

\section{Keywords}

Learner Autonomy, Simulation, Hotel Management, Hospitality, Task-Based Learning, Simulation-Based Teaching

\footnotetext{
${ }^{*}$ Corresponding author.
}

How to cite this paper: Jilani, S. F., \& Yasmin, M. (2016). Analyzing the Effectiveness of Simulation in Promoting Learner Autonomy: Perceptions of ESP Hotel Management Students. Psychology, 7, 1154-1162. 


\section{Introduction}

The hotel industry in Pakistan is gaining momentum and experiencing swift expansion leading to a brighter dawn. This evolution calls for basic organizational innovations and workplace skills to align opportunities and progress. Owing to this significant investment in skill-oriented approach, vocational training and prestigious educational programs, relevant to Hotel Management industry, at graduate and postgraduate levels, become a dire need of the day, in order to gear the wheel of the human capital. In this regard, higher education offers many opportunities in which adult learners can take part in order to meet specific needs i.e. learning a new job-related skill or preparing for a new career (Jaeger, 2004). One valuable string of Hotel Management programs offered by higher education department, along with other esteemed establishments, is entwined in University of Gujrat (UOG), Pakistan. The present study encompasses the teaching of English in one such skilldevelopment program-Bachelor in Hotel \& Restaurant Management (IHRM), offered at University of Gujrat. This IHRM program intends to equip the students in developing communication and interpersonal skills, team management and leadership skills, along with rigorous development of professional competence in a selfdirected milieu. "Hotel English" course taught at UOG, particularly focusing on communication skills, is a reflection of this endeavor, by means of which students are groomed in effectual oral communication skills which are integral part of this most sought-after hotel enterprise. This study, most specifically, analyzes the perceptions of students regarding the effectiveness of simulation as an "in-use" teaching methodology in promoting learner autonomy in the practical and operational interplay.

\subsection{Literature Review}

Learner Autonomy and Learner-Centeredness constitute a hub of Foreign Language teaching and learning for some thirty years. The focal point of learner autonomy was to place learner in the center by making him ambassador of learning while sharing the responsibilities and carrying out multifaceted choices in the learning process. Candy (1991: pp. 459-466) makes an attempt to profile the autonomous learners by presenting 100 abilities of autonomous learning under 13 subtitles: methodical/disciplined, logical/analytical, reflective/self-aware, curious/ open/motivated, flexible, interdependent/interpersonally competent, persistent responsible, venturesome/creative, confident/have a positive self-concept, independent/self-sufficient, skilled in seeking/retrieving information, knowledgeable about/skilled in learning, able to develop/use evaluation criteria. In addition, Van Lier (2008) highlights the "Janus-faced nature of autonomy" which encompasses two dimensions simultaneously, i.e. personal and social; to "myself" and to "the other". Thus, all these aspects of learner autonomy can be interpreted in terms of three dimensions: control over learning behavior, control over psychology of learning, and control over learning circumstances and the three dimensions are implicitly interdependent (Benson, 2001).

Moreover, for the promotion and endorsement of learner autonomy, a number of studies were carried out in different cultural contexts. In Pakistani context, where teaching English as a foreign language is an uphill task particularly in public sector which contribute to promote the orthodox traditional beliefs and values of relational hierarchy in classrooms; where self-confidence, collaboration, cooperation, decision making, and critical thinking approach may not foster; where learners do not share the control and responsibility side by side with the teacher; where fear may restrict their potential and where the learners do not feel autonomous to map out their own learning territories. Consequently, learners from such conventional set up really feel afraid when they come across proficient and efficient learners in the arena of learning (Tufail, Kanwal, \& Toor, 2015). Little (1991) adds in this regard that some teachers assume that the educational system in Asia is "so all-powerful and inflexible that autonomous learning can never happen” ( $p .40)$. In this perspective, Pathan, Sohail, \& Shahriar's study (2013), particularly with special reference to the University of Sindh and Sarwar's (2008) pro-autonomy approach in large classes throw light on the useful strategies that can assist learning and autonomy and counter attack the boredom and monotony in language classrooms i.e. Teacher training regarding learner autonomy, need-based curriculum, facilitation on the part of instructor and useful teaching and learning resources.

So, in the light of aforementioned scenario, it can be claimed that in the developing countries like Pakistan, the teachers and the learners being the chief stakeholders need to recognize their roles and responsibilities for the successful promotion of learner autonomy. This new set up entails willingness, zeal, vigor and negotiation to initiate and facilitate the participatory modes of collaborative learning, where both teacher and learner are ready to accept their new roles (Little, 1995). Thus, a teacher seeking to generate an autonomous learning environment should start off by giving small responsibilities to the students and gradually increasing their level of responsi- 
bilities and learning opportunities over time by engaging them in interactive activities like dramatization, role-playing and simulation imbued in real life contexts.

The central focus of the present study is also to analyze the effectiveness of Simulation as a teaching methodology in promoting Learner Autonomy. In the present study, simulation is associated with imitation as in roleplaying and dramatization. It is a teaching methodology employed by teacher in order to play certain roles without any training and it focuses on extempore performances. In this respect, Simulation can be defined as learning by doing (Schank, 1997). The terms simulation and role-playing are closely related to each other. Role play involves certain parts to be played within some specific situations where as, simulation involves certain complexities which later turn up in the form of conflict resolution by means of authentic scenarios. Also, simulation as a teaching strategy can be employed as an effective and dynamic scenario changer in second language learning. Hsu (2006) and Miccoli (2003) hold the view that such kind of dramatization enhances second language skill and proficiency, whereas Brauer (2002) reveals its significance in cross-cultural understanding. Murillo (2007) focuses on behavior of learners in the development of critical thinking skills through contribution in simulated drama activities while Dornyei (2009) observes that teacher's role as a facilitator becomes inevitable in such learning.

Hence, simulation, owing to its effectiveness as a teaching strategy, is progressively being used not only in military and industry, but also it has miraculous effects in the fields of medicine and nursing (Eaves \& Flagg, 2001). In the field of medicine, Okuda, Bryson, DeMaria, Jacobson, Quiones, Shen, and Levine (2009) examined around 100 articles and concluded that simulation-based training is more effective regarding procedural performance as compared to standard training. In the field of vocational teaching and learning Penfold, Kong, and Ma (2007) highlighted the development and use of virtual hotel for teaching hotel management through e-simulations which proved quite valuable in nurturing problem solving and interpersonal skills. Teach \& Govahi (1993) further explored the rating of four teaching methodologies-lectures, case studies, computerized simulations and experiential exercises (including role-plays). Findings highlighted that experiential exercises proved effective in the development of various skills like interviewing, conflict resolution and effective public speaking. Moreover, Yasmin (2014) also studied the role of simulation as a teaching strategy in the development of oral skills of undergraduate students of Hotel English enrolled in University of Gujrat, Pakistan. Her findings revealed that simulated situations have productive and positive role in developing oral skills. Moreover, simulation-based teaching motivates the students and helps them in the refinement of vocabulary, grammar, fluency and conversational strategies.

The present study is exclusively relevant to analyze the effectiveness of simulation in promoting learner autonomy with special reference to perceptions of ESP Hotel Management students of UOG. This particular vocational setting is emphasized owing to its popularity in the upcoming years. In this connection, learners in Hotel and Management should be geared up for the transformation that crops up in the industry and more prominently they need to learn how to learn. The present study is also valuable because it addresses the gap by taking both simulation and learner autonomy into account. It also attends to the perceptions, voices, beliefs and practices of students which are almost non-existent in the relevant literature. Moreover, the interrelationship of simulation and learner autonomy has not yet been explored, particularly in Pakistani context. Therefore, the study will be fruitful regarding its practical implications in language teaching and learning in order to enhance communication, interpersonal and workplace skills.

\subsection{Research Questions}

The present study deals with the following questions:

1) What is the role of "Simulation" and "Learner Autonomy" in English Language learning?

2) How far Simulation is an effective teaching strategy in promoting Learner Autonomy of Hotel English learners enrolled in BS Program?

3) What is the relationship between Simulation and Learner Autonomy?

\section{Research Design}

\subsection{Method of Data Collection}

Hotel English learners of BS program, studying at University of Gujrat, were comprised of the population of the 
study. They were all native speakers of Urdu and Punjabi, studying "Hotel English" for some specific purposes.

Purposive sampling technique was employed to select 40 students as a sample for the study, 10 of those were females while 30 were males. Purposive sampling, also known as "purposeful sampling" entails certain units or cases "based on a specific purpose rather than randomly" (Tashakkori \& Teddlie, 2003: p. 713) whether participants can and are keen to give information by means of their knowledge or experience (Bernard, 2002; Lewis \& Sheppard, 2006).

In order to accomplish the research goals, the researchers followed the Interactionist Paradigm and preferred a quantitative approach based on the survey method. Survey method is one of the most commonly employed methods in educational research. It engages researchers inquiring the questions of interest, interrelated to the research, from a significant number of respondents (Fraenkel \& Wallen, 2000). Thus, the researchers employed questionnaire for collecting and processing data for the study. The two sections of questionnaire were formulated on the pattern of extracting students' perceptions regarding the efficacy of simulation in cultivating learner autonomy in Hotel English learners. Following this, the first section was comprised of 10 items based on Simulation and the other section addressed 10 items on Learner Autonomy. Thus, the questionnaire consisting of 20 closed-ended, multiple choice items, based on a 3-point Likert scale, encompassing agree, disagree and neutral options, was designed. The items involved in the questionnaire were based on factual, behavioural and attitudinal statements (Dornyei \& Taguchi, 2010) and were adapted from previous research studies, chiefly concerning with those of Holec (1981), Dam, Eriksson, Miliander, \& Trebbi, (1990) and Little (1991). Further, the items of the questionnaire were constructed in the most precise, simple and in the best possible manner.

Moreover, to ensure the suitability and validity, the developed questionnaire was reviewed by the experts. The consistency and relevance of the items were guaranteed and thus the final version of questionnaire was constructed accordingly. Afterwards, it was piloted with 10 students who were not actually the part of the study. Besides it, the reliability check was carried out by means of a commonly employed statistic i.e. Cronbach's alpha, which evaluates the degree to which scales exhibit "uni-dimensionality". Bryman \& Cramer (2005) hold the view that .8 is the alpha level which signifies a good quality of conceptual relevance between items. But .7 is also considered as having good quality of items. The items in the questionnaire produced an alpha of .716 which guaranteed the reliability of data. Moreover, the questionnaire was self-administered by the researchers during a face-to-face interaction, in order to avoid errors. In this connection, 40 participants had been requested to fill out the questionnaires voluntarily. Hence, from this perspective, the researchers very meticulously considered the nuts and bolts of survey in order to guarantee lucidity and precision of outcomes.

\subsection{Method of Data Analysis}

The quantitative responses of the respondents are scrutinized by means of SPSS 16 in order to find out the relationship between simulation and learner autonomy. Moreover, the effectiveness of simulation as a teaching strategy and its role in promoting learner autonomy is also measured. Finally, the subsequent statistical methods and procedures were taken into account, complementing the research questions. Relative Frequency Distribution method was employed in order to get the general percentage of the respondents' responses regarding simulation and learner autonomy. Comparative study was intended to find out the significance of each variable in the cluster. Pearson Chi-Square Test was applied in order to establish the association and relationship between the variables i.e. simulation and learner autonomy and the level of significance for this test was at .05 . The key rationale of using this test is to find out the significance value of the variables. Whereas, likelihood ratio was calculated in order to ascertain the effectiveness of the variables. Finally, the results were illustrated by using tables and descriptions.

\section{Results}

\subsection{Demographic and Education-Related Characteristics}

In response to the research questions, the researcher investigated the relationship and effectiveness of simulation and learner autonomy by means of aforementioned statistical methods. The variables were separately examined in this regard. The outline of statistical analysis for the variables is shown in Table 1.

The following discussion is comprised of the students' responses and statistical outcomes presented in the 
Table 1. Analysis of students’ responses regarding effectiveness of simulation in promoting learner autonomy.

\begin{tabular}{crccc}
\hline Sr.\# & Items on simulation & Agreed & Disagreed & Neutral \\
\hline 1 & It helps me to learn by doing. & $42.5 \%$ & $12.5 \%$ & $45 \%$ \\
2 & It helps me to engage in group activities. & $50 \%$ & $20 \%$ & $30 \%$ \\
3 & It motivates me to use English language in a less & $57.5 \%$ & $15 \%$ & $27.5 \%$ \\
4 & threatening environment as compared to lecture method. & $35 \%$ & $42.5 \%$ & $20 \%$ \\
5 & It helps me to make collective decisions. & $42.5 \%$ & $12.5 \%$ & $20 \%$ \\
6 & It helps me to learn through Trial-and-Error method. & $7.5 \%$ & $72.5 \%$ & $30 \%$ \\
7 & It makes me feel comfortable when & $50 \%$ & $20 \%$ & $37.5 \%$ \\
9 & teacher does not interfere all the time. & $47.5 \%$ & $15 \%$ & $22.5 \%$ \\
\hline
\end{tabular}

above-mentioned Tables 1-3 respectively. These tables present a synopsis of students' responses, Pearson's Chi square value as well as likelihood value for the variables highlighting the relationship and effectiveness.

\subsection{Statistical Implications for Simulation \& Learner Autonomy}

Table 1 and Table 2 show that a vast majority of the respondents responded towards agreement. Further, Table 3 highlights that the value of Pearson Chi-Square was 4.302 and d.f. was 1 . Hence the significance value regarding the relationship between simulation and learner autonomy as the chief constructs of the questionnaire was .038 which is less than .05 . It clearly indicates that there is a relationship of association between two variables i.e. simulation and learner autonomy. Moreover, Table 3 demonstrates the effectiveness of simulation in promoting learner autonomy by means of Likelihood Ratio value which was 4.968 and d.f. was 1 . It clearly illustrates that the Likelihood Ratio value is also less than .05 which proves the effectiveness of simulation in promoting learner autonomy.

\section{Discussion}

In the present study, a vast majority of the students of IHRM showed their consent and agreement that simulation is undoubtedly an effective teaching strategy for Hotel English learners as it plays a dynamic role in promoting learner autonomy. The results of the study also threw light that the respondents reported each factor of simulation and learner autonomy differently.

The results of Simulation depicted in Table 1 clearly reflect that 17 respondents (42.5\%) were in favor that simulation as a teaching method focuses on learning by doing. It means that it focuses on experiential learning by means of self-discovery as well as scaffolding. 20 respondents (50\%) supported that simulation based teaching encourages group tasks and 14 respondents (35\%) further agreed that it also helps in making collective decisions. As engagement in such situations facilitate participants to observe and expand their own specialized value systems, become more tolerant of others, develop problem solving skills, and creatively explore subject matter (Ryan, Carlton, \& Ali, 1998). Only 11 respondents (27.5\%) were of the view that simulation based teaching helps in developing critical thinking skills. These critical thinking skills are nurtured in collaborative group tasks and problem solving situations. Moreover, 23 respondents (57.5\%) agreed to the non-threatening nature of simulated-learning environment as compared to the traditional lecture method. Davis (1993) states in this connection that by means of improvised dramatization in a non-threatening atmosphere, learners presume a character role, do and say things they pick out about that individual, and carry out behaviors without menace. Seventeen respondents (42.5\%) further showed consent that simulation enhances creative potential by means of processing and experimenting with language through Trial-and-Error method which paves the way for the success and competence in the task-based learning. Only 3 respondents (7.5\%) responded that teacher should not interfere in 
Table 2. Analysis of students’ responses regarding effectiveness of simulation in promoting learner autonomy.

\begin{tabular}{|c|c|c|c|c|}
\hline Sr.\# & Items on learner autonomy & Agreed & Disagreed & Neutral \\
\hline 11 & It helps me to set up my learning goals. & $67.5 \%$ & $15 \%$ & $17.5 \%$ \\
\hline 12 & It provides me chances to identify my strengths and weaknesses. & $72.5 \%$ & $12.5 \%$ & $15 \%$ \\
\hline 13 & It helps me to learn from my peers. & $67.5 \%$ & $15 \%$ & $17.5 \%$ \\
\hline 14 & It helps me to decide what to choose from outside the classroom for my learning. & $42.5 \%$ & $40 \%$ & $17.5 \%$ \\
\hline 15 & It helps me to become independent learner. & $60 \%$ & $22.5 \%$ & $17.5 \%$ \\
\hline 16 & It encourages the role of teacher as a facilitator. & $70 \%$ & $20 \%$ & $10 \%$ \\
\hline 17 & It provides me opportunities to learn through discussion. & $32.5 \%$ & $50 \%$ & $17.5 \%$ \\
\hline 18 & It stimulates my interest in English language learning. & $67.5 \%$ & $20 \%$ & $12.5 \%$ \\
\hline 19 & It helps me to offer opinions in the classroom activities. & $75 \%$ & $12.5 \%$ & $12.5 \%$ \\
\hline 20 & It helps me to become more self-directed in my learning. & $17.5 \%$ & $67.5 \%$ & $15 \%$ \\
\hline
\end{tabular}

Table 3. Chi-square test \& likelihood ratio.

\begin{tabular}{|c|c|c|c|c|c|}
\hline & Value & df & Asymp Sig. (2-sided) & Exact Sig. (2-sided) & Exact Sig. (1-sided) \\
\hline Pearson chi-square & $4.302^{\mathrm{a}}$ & 1 & .038 & & \\
\hline Continuity correction $^{\mathrm{b}}$ & 2.880 & 1 & .090 & & \\
\hline Likelihood ratio & 4.968 & 1 & .026 & & \\
\hline Fisher's exact test & & & & .060 & .040 \\
\hline Linear-by-linear association & 4.195 & 1 & .041 & & .489 \\
\hline $\mathrm{N}$ of valid cases $^{\mathrm{b}}$ & 40 & & & & \\
\hline
\end{tabular}

every classroom activity which means that the teacher's roles as facilitator is not very much encouraging in all sorts of activities regarding simulated-teaching and learning. In addition, 24 respondents (60\%) were of the view that simulation as a teaching method provides them ample chances to assess their learning by pointing out their flaws and weaknesses during observations which may further open room for improvement. Furthermore, 19 respondents (47.5\%) were of the view that simulation as a teaching method offers them opportunities to connect themselves to the outer world by means of real life situations which assist them in becoming life-long learners, having practical implications deeply rooted in the out of class scenarios. Most of these factors chiefly contribute in promoting simulation as an effective teaching method.

On the other hand, the results of Learner Autonomy as presented in Table 2 very lucidly demonstrate that almost all the factors of learner autonomy were also supported by the respondents. Also, these factors seem to be in line with those of simulation. The characteristics of learner autonomy simply complement simulated-teaching and learning which shows that both simulation and learner autonomy overlap each other. 27 respondents (67.5\%) were of the view that learner autonomy helps the learners in determining their learning goals and objectives. 29 respondents (72.5\%) highlighted that learner autonomy helps the learners to identify their strengths and weaknesses. In this respect, they seem to be the active agents in the process of learning thus monitoring their progressive modes and systematic development in the learning process. Twenty seven respondents (67.5\%) agreed that learner autonomy supports peer learning and 24 respondents (60\%) favored independent learning because both independent and peer learning cultivate motivating environment, thus building an environment of trust and confidence among the learners. In this connection, Vygotsky emphasizes the collaborative element of peer learning in terms of social autonomy. Hence, collaborative learning leads to "the development of a capacity for reflection and analysis, central to the development of learner autonomy, depends on the development and internalization of a capacity to participate fully and critically in social interactions” (Little, 1996: p. 211). 
Furthermore, 28 respondents (70\%) showed agreement with the teacher's role as facilitator with no omnipresence. Esch (1998: p. 37) points out regarding learner autonomy that:

"It is not self-instruction/learning without a teacher; ... it does not mean that intervention or initiative on the part of a teacher is banned; ... it is not something teachers do to learners; i.e. a new methodology; ... it is not a single easily identifiable behaviour...".

Moreover, 13 respondents (32.5\%) were of the view that autonomous learning provides them opportunities to learn through discussion, whereas, 30 respondents $(75 \%)$ responded that learner autonomy encourages them to offer opinions in classroom activities. In this perspective, it is apt to assert that learner autonomy is an interdependent business and a joint enterprise which assists learners to take charge of their own learning (Holec, 1981). Little (1996) opines in this regard that learner autonomy fosters the "capacity to make and carry out choices" and also it "develops a capacity for detachment, critical reflection, decision making, and independent action". 27 respondents (67.5\%) were of the view that autonomous learning stimulates their interest in English Language learning. Further, 17 respondents (42.5\%) were of the view that learner autonomy helps them to decide the extent of exposure in real life situations whereas, only 7 respondents (17.5\%) held the view that learner autonomy fosters self-directed learning. Such learners may have a deep rooted impact of traditional method in which teacher initiates and ends up every activity and where self-directed learning at the risk of the students is not much appreciated.

The overall results of the study imply that simulation as a teaching method plays an effective role in promoting learner autonomy of Hotel English Learners ultimately resulting in project management, communication and interpersonal skills. The results further accentuate a positive relationship between simulation and learner autonomy. It is also interesting to note that not even a single factor of simulation and learner autonomy was entirely discarded in relation to its effectiveness and mutual relationship which entails that both simulation and learner autonomy are interconnected and thus part and parcel of each other.

\section{Conclusion}

The purpose of the present study was to analyze the effectiveness of simulation as a teaching method in promoting learner autonomy in the light of the perceptions and beliefs of BS Hotel English Learners, enrolled in University of Gujrat, Pakistan. In the light of findings, it can be claimed that simulation as a teaching strategy not only furnishes the needs of Hotel English learners but also serves as an effective and valuable tool in promoting learning autonomy. Hence, in Pakistani context, there is a dire need to establish simulation-based-teaching in order to foster autonomous learning environment not only for the Hotel English learners but also for other Specific and Academic purposes. In this perspective, the curriculum and syllabus designers need to formulate policies and practices that address the teaching methodologies in connection with the refinement of communication skills and the growing concerns of the learners in the global world. Although, findings of the present study not only accounted for the effectiveness and success of simulation as a teaching methodology but also strengthened a positive relationship between Simulation and Learner Autonomy. So the need of the hour is to recognize the optimum utility of simulation as innovative and successful teaching methodology owing to its significance in English Language classroom. The study further lays emphasis that simulation is entirely experiential learning by means of which independent, peer and collaborative learning can be encouraged in connection with realia, along with minimum Teacher Talk Time (TTT) and maximum learning opportunities while monitoring the rate of learners' progress as well as pros and cons of their learning outcomes. It further nourishes critical thinking, decision making and problem solving skills in a cooperative and less threatening environment. Hence, all these features have dynamic relationship in endorsing and promoting learner autonomy.

Then, the outcomes of the present study develop deeper insights into the perceptions of students regarding effectiveness of simulation in promoting learner autonomy. This study may prove to be a useful and significant resource for EFL and ESL teachers and learners as it will open new avenues for fun learning. The study will also be a valuable asset for educationists, applied linguists and teachers because it reflects probable modifications in the teaching methodologies particularly in the mould of dynamics of entertaining activities of role playing, dramatization and simulation-based teaching and learning, by linking it to "out-of-class-learning". Moreover, it will not only broaden the scope of researchers while incorporating this teaching methodology in classroom of the learners having multiple learning styles but also be beneficial in relating and comparing it with other teach- 
ing methodologies in multidimensional fields. Overall, this study can be an effective whole that may add diversity to language teaching methodologies of other world languages pertaining to the efficacy of autonomous learning.

However, study is limited in scope with its small sample selected from one university. Hence, the results cannot be generalised. For a broader picture, other public and private institutes should also be included. It is, therefore, recommended for future researchers to include students and teachers as a sample from private and public institutions of Pakistan.

\section{References}

Bernard, H. R. (2002). Research Methods in Anthropology: Qualitative and Quantitative Methods (3rd ed.). Walnut Creek, CA: Alta Mira Press.

Benson, P. (2001). Teaching and Researching Autonomy in Language Learning. Harlow: Longman.

Bräuer, G. (2002). Body and Language: Intercultural Learning through Drama. Connecticut: Ablex Publishing.

Bryman, A., \& Cramer, D. (2005). Quantitative Data Analysis with SPSS 12 and 13. Routledge: London.

Candy, P. C. (1991). Self-Direction for Lifelong Learning. San Francisco, CA: Jossey-Bass.

Dam, L., Eriksson, R., Little, D., Miliander, J., \& Trebbi, T. (1990). Towards a Definition of Autonomy. In T. Trebbi (Ed.), Third Nordic Workshop on Developing Autonomous Learning in the FL Classroom. Bergen: University of Bergen.

http://www.warwick.ac.uk/go/dahla/archive/trebbi_1990

Davis, B. G. (1993). Tools for Teaching. San Francisco, CA: Jossey-Bass.

Dörnyei, Z. (2009). The L2 Motivational Self-System. In Z. Dörnyei, \& E. Ushioda (Eds.), Motivation, Language Identity and the L2 Self (pp. 9-42). Bristol: Multilingual Matters.

Dornyei, Z., \& Taguchi, T. (2010). Questionnaires in Second Language Research: Construction, Administration and Processing (2nd ed.). New York: Routledge.

Eaves, R. H., \& Flagg, A. J. (2001). The U.S. Air Force Pilot Simulated Medical Unit: A Teaching Strategy with Multiple Applications. Journal of Nursing Education, 3, 110-115.

Esch, E. (1998). Promoting Learner Autonomy: Criteria for the Selection of Appropriate Methods. In R. Pemberton, E. S. L. Li, W. W. F. Or, \& H. D. Pierson (Eds.), Taking Control: Autonomy in Language Learning (pp. 35-48). Hong Kong: Hong Kong University Press.

Fraenkel, J. R., \& Wallen, N. E. (2000). How to Design and Evaluate Research in Education. New York: McGraw-Hill Higher Education.

Holec, H. (1981). Autonomy in Foreign Language Learning. Oxford: Pergamon.

Hsu, M. (2006). The Effects of Dramatic Activities on Reading Comprehension of Senior High School: EFL Students in Taiwan. Ed. D. Dissertation, Kingsville, TX: Texas A \& M University.

Jaeger, A. (2004). Meeting the Special Needs of Adult Students. Journal of College Student Development, 45, 99-101. http://dx.doi.org/10.1353/csd.2004.0009

Lewis, J. L., \& Sheppard, S. R. J. (2006). Culture and Communication: Can Landscape Visualization Improve Forest Management Consultation with Indigenous Communities? Landscape and Urban Planning, 77, 291-313. http://dx.doi.org/10.1016/j.landurbplan.2005.04.004

Little, D. (1991). Learner Autonomy: Definitions, Issues and Problems. Dublin: Authentik.

Little, D. (1995). Learning as Dialogue: The Dependence of Learner Autonomy on Teacher Autonomy. System, 23, 175-182. http://dx.doi.org/10.1016/0346-251X(95)00006-6

Little, D. (1996). Freedom to Learn and Compulsion to Interact: Promoting Learner Autonomy through the Use of Information Systems and Information Technologies. In R. Pemberton, S. L. Edward Li, W. F. Winnie, \& H. D. Pierson (Eds.), Taking Control: Autonomy in Language Learning. Hong Kong: Hong Kong University Press.

Miccoli, L. (2003). English through Drama for Oral Skills Development. ELT Journal, 57, 122-129. http://dx.doi.org/10.1093/elt/57.2.122

Okuda, Y., Bryson, E. O., DeMaria, S., Jacobson, L., Quinones, J., Shen, B., \& Levine, A. I. (2009). The Utility of Simulation in Medical Education: What Is the Evidence? Mount Sinai Journal of Medicine, 76, 330-343. http://dx.doi.org/10.1002/msj.20127

Pathan, H., Sohail, A., \& Shahriar, A. (2013). Learner Autonomy: Building a Curriculum around Autonomous Learning with Exclusive Reference to the University of Sindh, Pakistan. Kashmir Journal of Language Research, 16, 83-93.

Penfold, P., Kong, W. F., \& Ma, H. (2007). Developing a Virtual Environment for Teaching Hotel Management Students. 
Proceedings of the International Association for Development of the Information Society Conference (E-Learning 2007).

Ryan, M., Hodson Carlton, K., \& Ali, N. (1998). Evaluation of Traditional Classroom Teaching Methods versus Course Delivery via the World Wide Web. Journal of Nursing Education, 38, 272-277.

Sarwar, Z. (2008). Taking the Bull by Its Horns: Pro-Autonomy Approach to Large Classes. IATEFL. http://iatefl.org

Schank, R. (1997). Virtual Learning: A Revolutionary Approach to Building a Highly Skilled Workplace. New York: McGaw-Hill.

Tashakkori, A., \& Teddlie, C. (2003). Handbook of Mixed Methods in Social and Behavioral Research. Thousand Oaks: Sage.

Teach, D. T., \& Govahi, G. (1993). The Role of Classroom Techniques in Teaching Management Skills. Simulation and Gaming, 24, 429-445. http://dx.doi.org/10.1177/1046878193244002

Tufail, R., Kanwal, A., \& Toor, S. (2015). Urdu Speaking EFL Students’ Problem in Learning English in Public and Private Schools of Punjab, Pakistan. http://rfh.org.pk/jur/paper

Van Lier, L. (2008). Agency in the Classroom. In J. P. Lantolf, \& M. E. Poehner (Eds.), Sociocultural Theory and the Teaching of Second Languages. London: Equinox.

Yasmin, M. (2014). Using Simulation in Teaching Oral Skills to Hotel Management Students. In S. Borg (Ed.), Teacher Research in Pakistan: Enhancing the Teaching and Learning of English (pp. 67-75). Lahore: British Council.

\section{Submit or recommend next manuscript to SCIRP and we will provide best service for you:}

Accepting pre-submission inquiries through Email, Facebook, LinkedIn, Twitter, etc.

A wide selection of journals (inclusive of 9 subjects, more than 200 journals)

Providing 24-hour high-quality service

User-friendly online submission system

Fair and swift peer-review system

Efficient typesetting and proofreading procedure

Display of the result of downloads and visits, as well as the number of cited articles

Maximum dissemination of your research work

Submit your manuscript at: http://papersubmission.scirp.org/ 